\title{
A!
}

This is an electronic reprint of the original article.

This reprint may differ from the original in pagination and typographic detail.

Kallio, Oskari; Masoodian, Masood

\section{Featuring comedy through ludonarrative elements of video games}

\author{
Published in: \\ ENTERTAINMENT COMPUTING
}

DOI:

10.1016/j.entcom.2019.100304

Published: 01/08/2019

Document Version

Peer reviewed version

Please cite the original version:

Kallio, O., \& Masoodian, M. (2019). Featuring comedy through ludonarrative elements of video games.

ENTERTAINMENT COMPUTING, 31, [100304]. https://doi.org/10.1016/j.entcom.2019.100304

This material is protected by copyright and other intellectual property rights, and duplication or sale of all or part of any of the repository collections is not permitted, except that material may be duplicated by you for your research use or educational purposes in electronic or print form. You must obtain permission for any other use. Electronic or print copies may not be offered, whether for sale or otherwise to anyone who is not an authorised user. 


\title{
Featuring Comedy through Ludonarrative Elements of Video Games
}

\author{
Oskari Kallio, Masood Masoodian* \\ School of Arts, Design and Architecture \\ Aalto University \\ Finland
}

\begin{abstract}
While humor exists in some shape or form in many video games, unlike in film and literature, comedy is not considered an established genre of its own in video games. One of the challenges in defining what constitutes comedy in video games, however, is in identifying the elements that contribute to such comedy, particularly with the inclusion of interactively as a fundamental aspect of video games. In this paper, we use the concept of ludonarrative-i.e., ludic (gameplay-related) and narrative (story-related) elements - as the basis for analyzing comedy in video games. We categorize the existing methods of incorporating comedy into ludonarrative elements of video games into three primary and five secondary methods, which we refer to as comic enhancers. We also illustrate the use of these methods through examples of existing video games, and provide a summary of our analyses and their implications.
\end{abstract}

Keywords: Video games, Computer games, Comedy, Humor, Narrative, Ludonarrative, Ludology, Visual design.

\section{Introduction}

Although the concepts of humor and comedy are deeply connected, they are not one and the same. Hookam and Mean [1] define humor as the "ability to perceive or express the intentional or unintentional comic elements of life", and comedy as the "intentionally structured cultural product that employs particular forms and conventions to create the affect of amusement in an audience." Martin [2], on the other hand, defines humor as "a ubiquitous human activity that occurs in all types of social interaction. It infuses meaning to the meaningless and takes it away from matters that are perhaps too meaningful.", and suggests that while humor has biological roots in our genes, cultural norms and learning define how it is manifested in individuals.

\footnotetext{
${ }^{*}$ Corresponding author

Email address: masood.masoodian@aalto.fi (Masood Masoodian)
} 
Beyond defining comedy and humor at an abstract level, related research in these areas is limited. The problem with conducting such research is that it seems comedy and humor reject closer inspection and theoretical analyses. As Eastman [3] points out, from reading the serious-sounding descriptions of humor by humor theorists, one would not get a picture of it as a playful, lighthearted activity. Similarly, E.B. White [4 has famously stated, "Humor can be dissected, as a frog can, but the thing dies in the process and the innards are discouraging to any but the pure scientific mind."

While various humor theories exist - such as Monro's division of superiority, incongruity, and relief theories [5] - most (e.g., see [6]) only attempt to describe what is at the core of a humorous experience. As such, there are no accepted unified theories of humor, nor any precise formulas for humor creation-only some intuition. In general, the underlying patterns in something considered as "funny" remain a mystery, and any humor theory basically attempts to reverse engineer humor, by taking apart the thing that has been previously accepted as "funny". Ultimately, however, humor comes into existence only through its performance. Eastman [3] points out that humor is a form of play in itself, and that "No definition of humor, no theory of wit, no explanation of comic laughter, will ever stand up, which is not based upon the distinction between playful and serious."

If humor and comedy are in general rather difficult to define, the addition of the interactivity elements of video games 1 make it even more challenging to define humor and comedy in the context of video games. Unlike other entertainment media such as films and books, video games are usually categorized by the loops of their gameplay rather than necessarily the emotions they evoke in their players. It is not, therefore, surprising then that while words "comedy" and "humor" are commonly used to describe specific genres of films and books, they are hardly ever used to describe video games. Furthermore, although "humor" is a prevalent element in many games, only a few of them seem to warrant the "comedy" label.

However, the few comic video games that do exist, are proof of the comedic capability that this medium holds. In fact, in many ways the medium of video games is perfect for comedy - since with their means of play, video games can actually involve their players in the act of comedy-making. Despite this, while most video games are naturally considered to be "fun" to play, very few are touted as being "funny". Video games evoke feelings of joy upon triumph and feelings of disappointment upon failure, but the wider emotional scale is often under-represented.

Hookam and Meany [1] note that for video games' comedy to be recognized as a genre, there must first be a consensus on the elements that contribute to such comedy. Our research is working towards this goal by analyzing and categorizing comic elements of video games, using the underlying concept of

\footnotetext{
${ }^{1}$ The term "video games" is used here to also refer to other alternatives such as "computer games", "console game", "browser games", and "mobile games".
} 
ludonarrative. The term "ludonarrative" has been coined by Hocking [7] - a game designer himself - by combining the Latin word ludus - roughly translating to "game" - with the word narrative - referring to a meaningful recount of connected events - to refer to the junction of gameplay and narrative elements in video games.

In our previous work [8], we have defined three primary methods used for incorporating comedy elements into ludonarrative of video games - namely their visual style, sources of comedy, and conflicts in their comedy. In this paper, we extend this work by discussing several other secondary methods, referred to here as comic enhancers, in addition to those primary methods. We also provide a summary of our analyses, and a discussion of their implications and the resulting conclusions.

\section{Ludonarrative comedy}

Despite their importance, major literature reviews and analyses of humor and comedy in video games are scarce. Dormannn and Biddle 9 provide the first of such reviews, focusing primarily on the gameplay elements. More recently, Dormann [10] has extended this work, while still keeping the focus on humor in gameplay.

Perhaps the most comprehensive review of humor in video games to date, however, has been that of Grönroos [11, which identifies the role of player input in comedic aspects of video games, and relates this to game characters, game worlds, and game mechanics, as means of offering emergent humor. Further to these, she also reviews the role of scripted (i.e., narrative) humor in video games. Based on her analyses, Grönroos then suggests that the apparent lack of humor in video games may be a question of recognition - with interactive humor taking new unfamiliar forms: "games use humor in ways that are unfamiliar from other media, and often humor elicits amusement instead of laughter."

For an initial observer, ludonarrative comedy may not seem to differ much from traditional comedy where narrative sequences unfold chronologically. However, games are fundamentally different from other traditional media, and as such, ludonarrative elements of games provide many different opportunities for inclusion of comedy. Games are enthralling, player-influenced and effortrequiring rule-based systems with variable and quantifiable outcomes that, while have values assigned to them, also have negotiable consequences [12. Frasca [13. emphasizes that the "player agency" is what distinguishes interactive narratives of games from traditional narratives of other media: "Observers [of other media] are passive, the player [of a game] is active. If the player does not act, there will be no game, and therefore no session at all." Frasca also stresses that "play" and the "narrative" are not one, but play can lead to the creation of a narrative - one which we prefer to here as "ludonarrative".

Despite many new alternative opportunities for inclusion of comedy, ludonarrative comedy also generates its own unique design problems which need to be addressed. For instance, comic timing - the fundamental and unforgiving factor in any kind of comedy - can be easily impaired by the player in an interactive 
game environment. Therefore, the designers of comedy video games need to fully understand the strengths and weaknesses of this particular medium.

In comparing the neglected video games comedy to the established horror video games genre, Quinn 14 argues that the barriers to successful video games comedy are not mechanical in nature. She also points out that horror and comedy share many of the same qualities - they aspire to take their audience by surprise, with both there is usually a set-up and a pay-off, and the design problems are similar (e.g., the efforts to keep the material fresh). Quinn suggests that only by considering comedy as a mechanical foundation for gameplay, as well as having a firm understanding of what drives humor, the potential of video games' comedy can be realized.

It is perhaps due to this lack of understanding the fundamentals of ludonarrative comedy that most developers still seem to avoid designing their games primarily around humor, and often use it like a seasoning to add flavor to the end result - with little relevance to the overall design. Pratchett (quoted in [15]) stresses that this sort of approach does not lead to true comedy: "Good humor needs to be built in. It should be the chocolate chips in the gooey cookie of gaming, rather than chocolate sprinkles on top."

Full commitment to comedy is also seen as a risk, because a "bad" comedy has no value. A funny joke is a source of joy, but a bad one can be downright detrimental. Bell [16], having studied responses to failed humor, proposes that the reason a bad joke makes the listeners angry is because it is often taken as an insult to the audience's sense of humor: "When a joke is actually funny, listeners don't mind the disruption because there is a payoff: humor. Without the humor, listeners may become annoyed at the lame crack."

Furthermore, it is also difficult for non-integral comedy to make it all the way to the final product, simply because of the way most games are designed and developed. A substantial part of this process involves the trial-and-error based approach to playtesting. Constant playtesting equals repetition, which is known to sour even the funniest of jokes. Humor is a transient delight. Repetitionwhen used correctly - is a comic enhancer, but without variation it can make the humor disappear. Root (quoted in [17]) highlights that "Surprise is one of the keys to comedy, and it's difficult to pull off in a game with repeat plays." Gameplay benefits from repetitive actions as the player gets better at performing them, but as games go through quality control and hours of playtesting, jokes are the first ones to be disposed of since they do not stand retelling. Schafer [18] also emphasizes that game designers must be hypersensitive about repetition: "There is an old expression, don't put humor on the inner loop. Nothing is funny that many times in a row. OK, I just made that up but it's true. Characters need to change up what they say, not just to keep the humor fresh, but to make the character seem more real." Quinn [14 compares playtesting for comedic games to stand-up comedians who are constantly refining their material with fresh audiences: "Test early, test often and with new people." Therefore, the role of playtesting should not be about discarding comedy, but making it funnier.

Abbott [19] argues that comedy is "cerebral, technical, and deeply human", and notes that, of those three factors, comedic video games often stumble in the 
"deeply human" department. Abbot supports his claim with the gradual disappearance of comedic games towards the beginning of the new millennium, when video game visuals started transitioning from primitive to more photorealistic. He links this observation to the "uncanny valley" theorem, which maintains that the closer a human replica gets to a real human, the more unnatural it appears to the (human) observer: "The uncanny valley is nobody's friend, but it's an especially harsh environment for comedy." When games fail the comedic Turing test, it is likely that something about their humor is too foreign or unrecognizable to be considered funny. While the player can be used to fill the "deeply human" void in ludonarrative comedy, there are many fundamental, and largely unaddressed, problems in using the player as a component in a comic gameplay. At the very least, in such cases when players' efforts result in failure, they are more likely to end up being disappointed rather than amused. Failure can be turned into comedy, as long as the players themselves are not the laughing stock.

Therefore, one of the key questions in ludonarrative comedy is how to make the players commit to comedy. Totilo [20 calls attention to the dualistic roles the players are given in video games. Players are not only members of the audience, but are also playing the part of the lead actor. When the objectives of a game are clear and the gameplay revolves around active verbs, players can be expected to play their part, but when the concept of "nuance" is introduced, requirements for the players' performance increase. As Totilo points out: "It's easy for a game designer to make someone feel like Bruce Willis or Sly Stallone by

putting a virtual gun in their hand. But how do you go about making someone feel like Charlie Chaplin or Bernie Mac? Can you make a gamer actually commit comedy?" 20].

\section{Primary methods of ludonarrative comedy}

As mentioned earlier, we have previously [8] defined, and illustrated through examples, three primary types of methods used for incorporating comedy into ludonarrative of video games. In this section we briefly summarize each of these three primary types - i.e., visual style, sources of comedy, conflicts in comedybefore moving on to introduce the secondary methods - i.e., comic enhancers - in the next section.

\subsection{Visuality of comedy}

Humor has a visual dimension, which according to Morreall 21 is the basis of all comic experiences. Gordon [22] describes humor as being "aesthetic to the extent that it arouses the viewers' imagination, provides them with insights about human existence, and provokes them to think more critically and creatively." Because video games are a visual medium, aesthetics have an important role in their delivery of humor, either to tell visual jokes, or prepare the player for comedic experiences. Visual cues, such as the overall visual style, 


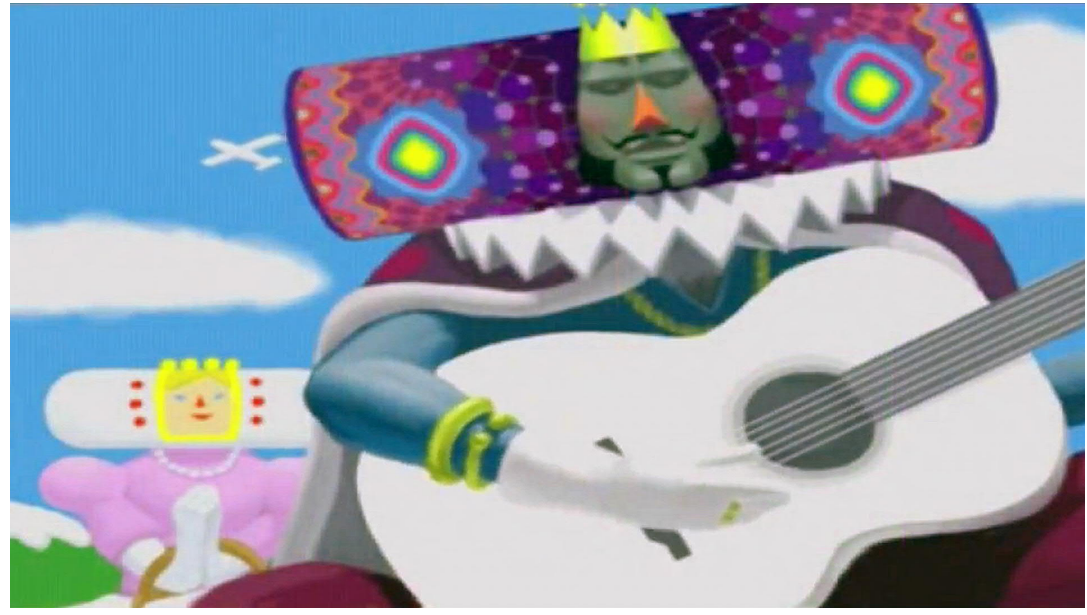

Figure 1: A screen-shot from Katamari Damacy, showing its comic visual style.

character design, and animations can condition the player to get into a humorous mood. Katamari Damacy ${ }^{2}$, for instance, utilizes all these visual elements to highlight the eccentricity and comic nature of its ludonarrative (see Figure 1).

Video games also share many similarities with animated films, in that they both use their fantastical canvas to portray any imaginable idea. Tex Avery, a longtime animation director for Warner Bros ${ }^{3}$, is responsible for both inventing and institutionalizing a great number of visual gags, that have since become standard visual language in narrative animation. Even now, contemporary video games utilize Avery's comedy techniques to make their players laugh. For instance, the Outcast 4 video game jests at deficiencies of the digital medium with a pretend blooper reel with simulated bugs and glitches.

In contrast to Avery, his successor at Warner Bros., Chuck Jones emphasized creative discipline in cartoons [23, by establishing and using a clearly defined set of rules for animations [24]. He is quoted [25] as saying: "If you can't tell what is happening by the way the character moves, you're not really animating." For video games, Jones' structural approach is easier to adapt than the boundlessness of Avery's method, because games themselves are closed formal systems. Super Mario Odyssey 5 provides a good example of animations that instantly tell the player what is happening. Mario is able to "capture" various enemies in order to control them. With each creature behaving and controlling in a comically distinct manner, the player gets instant feedback of their abilities.

Comedy can also be generated purposefully through bad- or cheap-looking

\footnotetext{
${ }^{2}$ Namco (2004), Playstation 2.

3 https://www. warnerbros.com

${ }^{4}$ Intogrames (1999), Windows.

${ }^{5}$ Nintendo (2017), Nintendo Switch.
} 


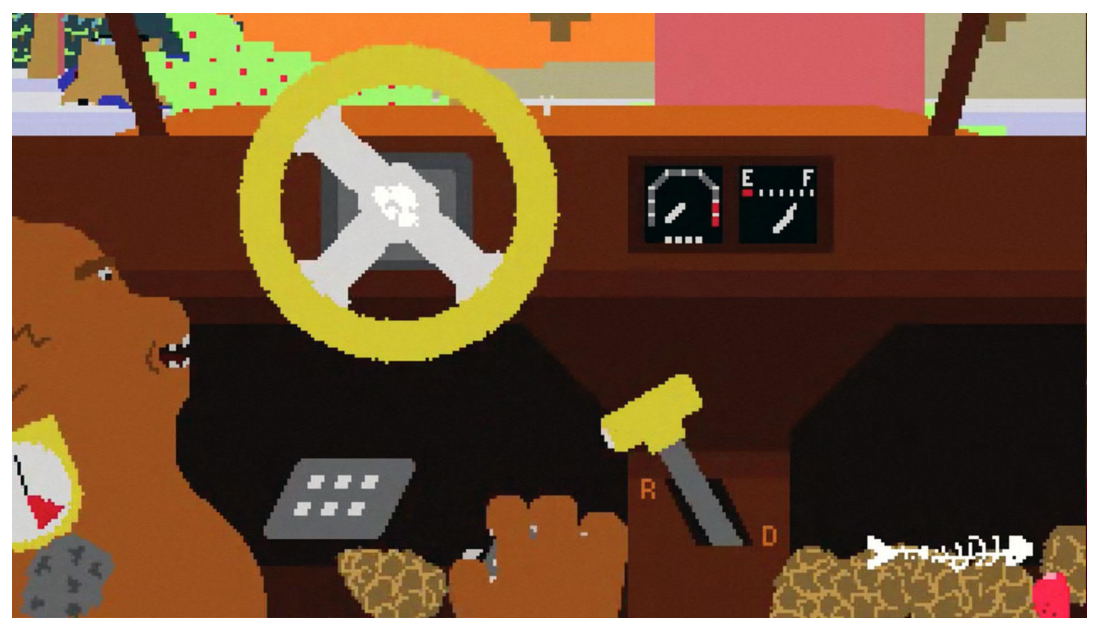

Figure 2: A screen-shot from Enviro-Bear 2000, showing its cheap-looking visual style.

visual design and animation. Terry Gilliam's animation transitions in Monty Python's Flying Circus 5 and the animation series South Park $[7$ are good examples of comedy through clumsy cut-out animation. Many low-budget games, having realized this, utilize intentionally bad animations and character designs to amuse their players. For instance, Surgeon Simulator 8 uses its coarse visual presentation to promote its funny gameplay premise, and to differentiate itself from the more serious simulator games. Similarly, Enviro-Bear 200d9 elevates the comicality of its premise with purposefully cheap-looking visuals, and clunky controls (see Figure 2). An overly simplified visual style can be funny in itself, but it can also be used to increase emphasis on other funny areas of a given game, and furthermore can lead to heightened self-reflexivity [26].

\subsection{Sources of comedy}

The choice of who conducts the comedy in a video game largely defines the type of its ludonarrative comedy. Salen and Zimmerman [27] divide video game narratives into two types, embedded and emergent narratives. Embedded narrative is all the information the game wants to transmit to the player, whereas emergent narrative arises from the player interacting with the rules and the mechanics of the game. Game designers have direct control over embedded narratives, but only indirect control over emergent narratives.

Cook [28] postulates that game designers approach video game comedy design in similarly distinct ways. The first approach, humor-through-storytelling,

\footnotetext{
${ }^{6}$ Monty Python's Flying Circus (1969-1973), BBC1 (1969-1973) and BBC2 (1974).

${ }^{7}$ South Park (1997), Comedy Central.

${ }^{8}$ Bossa Studios (2013), Windows.

${ }^{9}$ Captain Games (2009), Windows.
} 


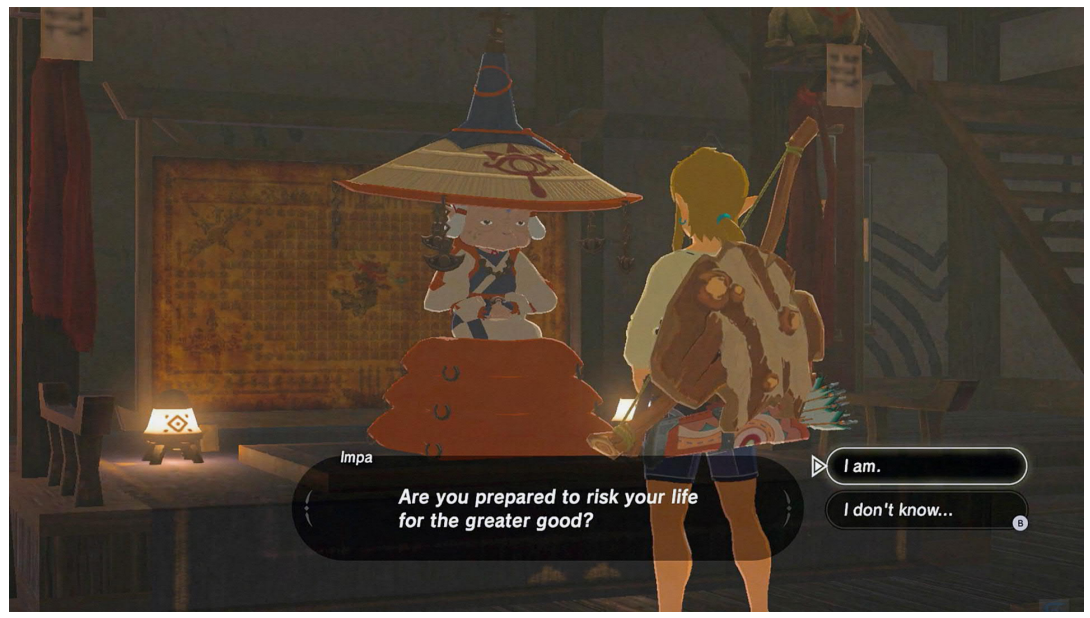

Figure 3: A screen-shot from The Legend of Zelda: Breath of the Wild, showing its melancholic storyline world.

is a traditional one in which comedy is executed through conventional means of storytelling, including humorous writing, comic scenarios, and visual jokes. For example, the Grand Theft Auto games, such as Grand Theft Auto: San Andreas 10 establish their humorous satirical world with help from various audiovisual cues. The player's daily existence in the game is filled with satire and parody, which are included in the many radio shows, advertising signs and fictitious brands of the game. In The Legend of Zelda: Breath of the Wild11. on the other hand, humor is used to cut through the melancholy of the main storyline, which is set in a war-weary world (see Figure 3 ).

The second approach, humor-through-mechanics, is unique to interactive entertainment. This method involves the player as part of the "comedy-making" process by establishing gameplay mechanics or activities designed to cause comical conflicts (see below). For instance, The Stanley Parable $\epsilon^{12}$ is an exploration of the joy found in rebellion. The game deliberately sets up a conflict between the narrative and the gameplay - sometimes referred as ludonarrative dissonance [7]- to produce comedy.

The third type of ludonarrative comedy, unintentional comedy, is one without a clear agency. This type of humor is found in the corruption of the game itself, in the form of bugs and glitches. They represent what Knox [29] regards as the essence in all humor, "playful chaos in a serious world." Because unintentional comedy is a surprise to both the player and the game designer alike, it is one of the more clear examples of incongruous humor in video games. In-

\footnotetext{
${ }^{10}$ Rockstar Games (2004), PlayStation 2.

${ }^{11}$ Nintendo (2017), Nintendo Switch.

${ }^{12}$ Galactic Cafe (2013), Windows.
} 
congruity theory [6] considers laughter as an effect that arises from the friction of two or more contrasting concepts. The bisociation, as Koestler [30] calls it, is a result of a shock effect that occurs when the two incompatible matrices conflict with the mind's expected and create a comic effect. The incompetency of a game (or its designer) to perform tasks - malfunctioning physics engine or outlandishly twitching animations - can turn a serious game into an accidental comedy. However, as Švelch [31] suggests, games that strive to represent real life but end up failing may become a subject of ridicule. Accidental comedy comes at the cost of taking the player away from the intended experience, which is why games seldom wish to be the subject of ironic laughter.

\subsection{Conflicts in comedy}

Vorhaus [32] asserts that comedy lives in the gap between the comic reality and the real reality. This gap - referred to as the comic premise - is a deliberately chosen point of view that is meant to reveal something humorous in a situation. Vorhaus outlines three types of comical conflicts that lead to the comic premise: (1) the inner conflict is about a character at war with itself, (2) the local conflict is an interpersonal dispute between two or more characters, and (3) the global conflict is between a character and the world it is part of. The local and global conflicts can be identified in most comedic games. The inner conflict, being the most introspective of the three, is probably the rarest one to encounter. The three conflicts often overlap, which is why they are referred to as layers. Vorhaus asserts that the conflicts are capable of casting a light of truth onto a scene: "the comic reality reveals the truth in the 'real' reality." A well-known comedy axiom, from Truth in Comedy [33, claims that the "Honest discovery, observation, and reaction is better than contrived invention."

The inner conflict is about exploration of the character and its emotions [32, and because the character is at war with itself as opposed to something external, the surrounding world does not often understand its behavior. Therefore, incorporating the inner conflict as part of gameplay can make the player an active part of the character's psychological struggle. Dille and Platten [34] posit that through gameplay, a video game can show proportionality to the players and provide them with metrics by which they can measure their progress. If turning everyday objects and scenarios into play is, as Bogost 35] argues, an inarguable strength of the medium, mundane circumstances can make a game as interesting as anything. Octodad: Dadliest Catch ${ }^{13}$, for instance, exemplifies how contrasting the players' intent with their actual performance can reveal something about the inner conflict of the playable character. The central character of the game, Octodad, is an undercover dad in a regular human family doing his utmost to conceal his true identity, which is that he is in fact an octopus.

The local (interpersonal) conflict can be seen as a battle between two individuals [32] - with one of the characters being comical, and the other being the

\footnotetext{
${ }^{13}$ Young Horses (2014), Windows.
} 


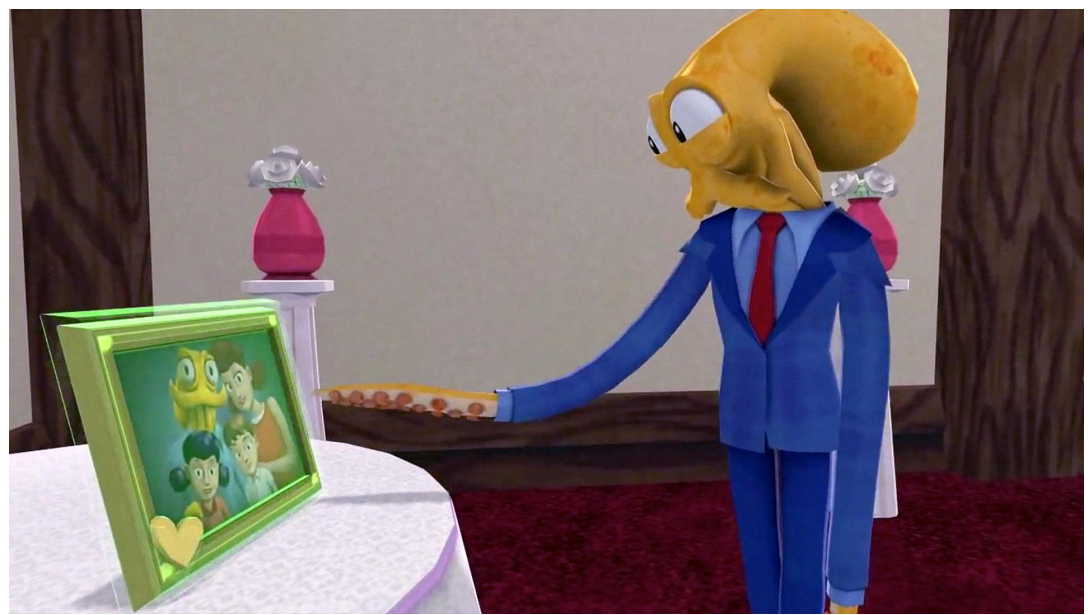

Figure 4: A screen-shot from Octodad: Dadliest Catch, showing its conflicting world.

more serious in contrast. The characters involved might compete for a shared desire, or simply cross paths and collide while pursuing their own separate goals. For example, Untitled Goose Game ${ }^{14}$ finds comicality in the colliding interests of two characters, in which the player controls a wayward goose whose only goal is to torment an unsuspecting groundskeeper trying to do his job. The interpersonal conflict is also well-suited for communal comedy, where two or more people are assigned roles with unambiguous objectives. Simply situating players in the same space creates a conflict between them. Such is the case with Who's Your Daddy ${ }^{15}$, an asymmetrical multiplayer game about the stress of babysitting. One person plays a parent in a race against the clock to baby-proof a household, while the other player controls an infant whose aim is to drain its health to zero in any imaginable way. Vincent [36] describes the emotional core of the comedy of this game as: "Babysitting is a hard job because babies are irresponsible. They'll drink whatever's under the sink and stick forks in power outlets. It's not that they don't want to live, they just don't understand how life works."

Finally, the global conflict refers to the dispute between characters and the world they inhabit. Vorhaus 32 divides the global conflict into two scenarios: (1) where a normal character is part of a comical world, and (2) where a comical character is situated in a normal world. As video game worlds are all more or less fictional, the latter scenario, where the world is normal, is rare to come across. Games like Gang Beasts 5 , The Sims 4 , or even the Porta 18 , that accentuate

\footnotetext{
${ }^{14}$ House House (Release date 2019), Windows, macOS, and Nintendo Switch.

${ }^{15}$ Evil Tortilla Games (2015), Windows.

${ }^{16}$ Double Fine Productions (2017), PlayStation 4.

${ }^{17}$ Electronic Arts (2000), Windows.

${ }^{18}$ Valve (2007), Windows.
} 
comedic character interactions rather than the comicality of the world, could be counted as examples of such scenario. However, it could be argued that each of these games also contain a comical world, due to them deriving from real world norms. In contrast, Katamari Damacy ${ }^{19}$ is a portrayal of an interactive comical world (see Figure 1). Similarly, Frog Fractions ${ }^{20}$ challenges game design conventions by making its gameplay sequences illogical.

\section{Secondary methods of ludonarrative comedy}

Further to the above mentioned primary means of creating ludonarrative comedy, various comic enhancers - based on the concept of "humor enhancers" [37 - can be used in video games as secondary methods of incorporating comedy. These secondary methods are not only useful for captivating the players' curiosity, but can also prepare them for the full experience of humor 38.

Through these comic enhancers, game designers can highlight the comic premise of a game, and indirectly address the current state of affairs of the game world to the player. The setting in a video game contextualizes and justifies the player's actions in it. Video game worlds are hypernormalized realms, or as Huizinga [39] - and later, Salen and Zimmerman [27] - defines it, artificial spaces that suspend and replace the reality of the world and what is considered normal in it. Games wish their players to accept the implausibility that these worlds hold, hoping that they would not question the artificial rules and boundaries of the game worlds. Video games have the responsibility to fascinate their players, because due to their freedom of movement, narrative details may hinge upon the players noticing them.

Interestingly, comedy can be regarded as a means of captivating audience's attention, as it is an exceptionally charismatic way of conveying narrative information to them. But in order for comedy to work as intended, it often requires to be highlighted. In video games, comic enhancers can be used as cues to highlight the ludonarrative comedy. The cues do not necessarily have to be funny on their own, but they must help the player to perceive something that is meant to be funny - similar to a humor enhancer as a narative technique [37.

As such, we define the role of comic enhancers as being secondary, often used as complimentary methods in the context of the primary methods defined earlier. In this section, we present some of these secondary comedy methods used in video games, and explore their relation to the game world and the player.

\subsection{Humorous worlds}

Marszalek [38] calls narrative worlds that project a general impression of humor as "humorous worlds". These worlds, she argues, comically intensify certain elements that appear in them. Although Marszalek's concept of humorous worlds stems from literary works and her samples are collected from various

\footnotetext{
${ }^{19}$ Namco (2004), Playstation 2.

${ }^{20}$ Twinbeard Studios (2012), Browser game.
} 


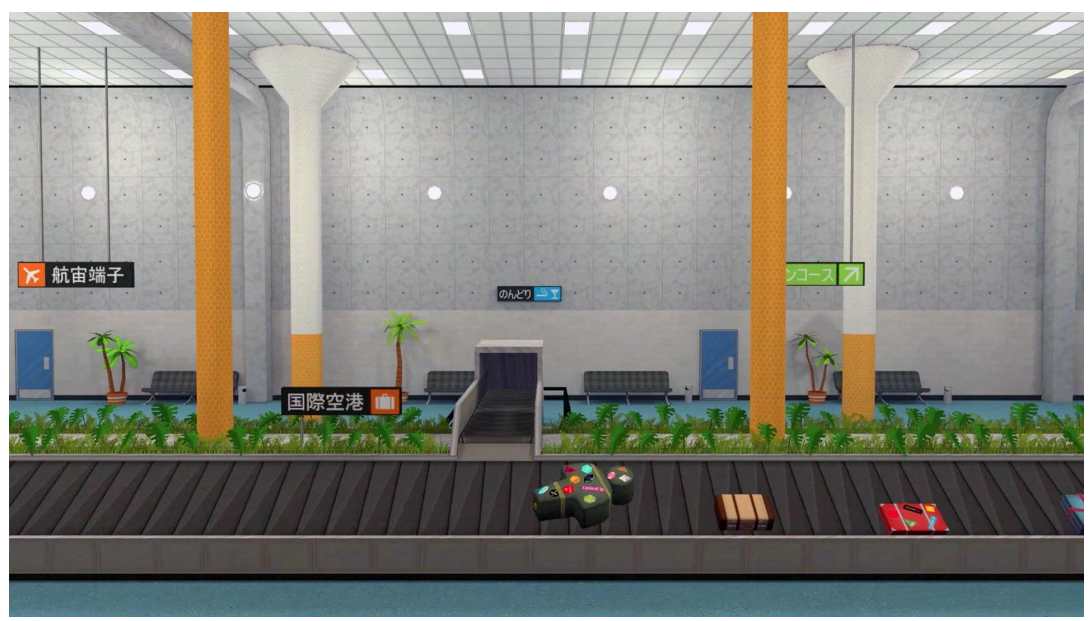

Figure 5: A screen-shot from Jazzpunk, showing its humorous world.

novels, many of her conclusions can be applied to video games as well. What makes video games different from other media is that the players can actually spend time in their respected virtual worlds - i.e., they are like physical spaces where the player lives. A comedic video game ideally encourages and reacts to the players' humorous aspirations. According to Marzalek 38, the longer the comedic narrative is, the more work is required to establish a "joking relationship" with the audience. This the reason as to why jokes, due to their concise form, are more distinctly identified as humorous discourse than novels. Similarly, smaller and more focused comedic games convey their humorous intentions far better than bigger games that demand days of playtime. For example, every facet of the concise video game Jazzpunk ${ }^{21}$ reminds the audience of its comedic focus (see Figure 5p. It does this through a steady delivery of self-contained little gags. The jokes in the quasi-open levels are practically distributed in a checkerboard pattern, where every other square contains a joke, unrelated to other jokes in the world. The gags of Jazzpunk are mostly not funny enough to make a person laugh, but at least they come in steady intervals.

An attempt at humor has to be understood as an intended deviation from normal (to be discussed later) for it to be effective. To figure out a joke, a listener has to understand it to be non-literal, even untrue. Mulkay [40] states that humans interact with each other in two very different communication modes, in a serious and in a humorous mode. According to him, the countless deep-rooted contradiction in human communication led to the evolution of the humorous mode. The humorous mode gets activated when a person notices contradictions, incongruities, or errors in the regular patterns of behavior - what they consider normal. Furthermore, Marzalek [38] asserts that humorous mode is

${ }^{21}$ Adult Swim Games (2014), Windows. 
the state where humorous narratives are interpreted most effectively. It is a result of carefully positioned cues by the author about the comedic nature of the material. When a game world is viewed as an entity communicating with the players, it can be used to influence the players' mood, and to get them in a humorous mode. This can be done by establishing a level of normality, following a subversion of the established code of conduct. In video games, normality can be communicated by how the world reacts to the player-controlled character, or how the character reacts to the actions of the player. As we will discuss later, normality can also be challenged to create comedy.

\subsection{Environmental storytelling}

Environmental storytelling is non-textual story progression, which is a popular method of telling and expanding stories in video games. The style is popular due to its suitability for the medium. Jenkins [41] applauds environmental storytelling for creating pre-conditions for engaging narrative experiences by evoking pre-existing narrative associations, providing a staging ground for narrative events, embedding narrative information within the arrangement of the scenery, and providing resources for emergent narratives. It is a form of storytelling that never interrupts the flow of the gameplay. In addition, the players themselves can choose how much, or how little, they want to learn about the game world. There is a story in the ambiance, and it is for the players to unearth and reconstruct it - that is, if they have the motivation to do so.

A well-crafted world provides a strong foundation for environmental and situational humor. Environmental comedy utilizes similar building blocks to many jokes. However, when comedy is integrated into the environment, the placement and the arrangement of the comedic fragments require careful planning and precision. One of Marszalek's 38 main assertions is the importance of "repetition and variation" as a comedy-enabling instrument. The technique that works in jokes - the initial set-up, repeated set-ups, and the pay-off or punchline - can also be applied to comedic world-building. Repetition establishes the world and how normality manifests itself in it, while variation in the pattern can make it humorous and unveil comedic abnormality. Variation is the resolution for the joke, and ideally comes from outside the range of the observer's expectations. The reveal of the affable deception releases tension and usually results in laughter - or at least in a smile. It is important that the player witnesses at least the initial set-up, and the final punchline. As such, these are required to be placed in the game in a way that they are impossible for the player to miss.

Critics have pointed out that environmental storytelling is not exactly interactive, if all that the player does is detective work by connecting narrative fragments inside their head. In an article, provocatively titled "Video Games Are Better Without Stories", Bogost [35] questions whether environmental storytelling in games are really telling "stories", when they are merely presenting the "environments". His argument is built around the assumption that each medium has an aesthetic foundation and everything, including stories, should derive from that. He elaborates on this by saying: "Poetry aestheticizes language. Painting aestheticizes flatness and pigment. Photography does so for 
time. Film, for time and space. Architecture, for mass and void. Television, for economic leisure and domestic habit." Furthermore, he goes on to suggest that the games are true to their aesthetic foundation when they turn everyday objects into play, "Take a ball and a field: you get soccer. Take property-based wealth and the Depression: you get Monopoly. Take patterns of four contiguous squares and gravity: you get Tetris." However, Bogost ignores the fact that games are able to tell stories that would not be as compelling or interesting, had they been told in any other medium. Moreover, his critique also overlooks the narrative aspect of play-i.e., games are effectively stories. A ball and a field do not turn into a game of soccer without the make-believe aspect of a game -i.e., its narrative framework. Moreover, a soccer game is far more enjoyable when the observer is aware of the history of the players and the dynamics of the two teams. One could argue that, for all intents and purposes, a soccer match, with its rules deriving from imagination, can be seen as a work of fiction.

The world cannot be stripped from stories, as they are so central to the human existence. Lebowitz and Klug [42] point out that should game designers abdicate their authorial responsibility to tie gameplay into story, the players will compile a story themselves to put their actions into context. Shermer [43] claims that humans are predisposed to infuse meaning, intention and agency to patterns that lack them. Furthermore, Rose [4] describes stories as recognizable patterns, in which we seek meaning: "We use stories to make sense of our world and to share that understanding with others. They are the signal within the noise." Therefore, while games may not need stories but their players do. Walker [45] considers storytelling as a solution to the rationalization problem that each new game set-up and its artificial rules create: "we invent new problems so that we can solve them with new stories." Similarly, comedy can be seen as a solution rather than a design problem. After all, people are always inclined to seek reasons to laugh. The lack of comical awareness, much like the lack of story, does not make a game unplayable, but it can make the player seek hilarity from unwanted places. Therefore, due to players' active presence in games, humor is not something that can be simply removed from them.

\subsection{Challenging normality}

When de-constructed, all comedy seems to either directly or indirectly reference what is considered to be truthful or normal within its frame of reference. For instance, slapstick exceeds the boundaries of normal behavior, parody and satire de-normalize pre-existing authoritative messages through imitation, and observational comedy illuminates the mundane aspects of everyday life that have become invisible to us. Mulkay [40] affirms humor being a form of indirect communication, that aims to transmit implicit, positive or negative messages to others in order to influence their way of thinking or behaving. Not only is the baseline of normalcy hidden in humor, but it is also vital for the observer to comprehend it.

According to Bergson [46], laughter, or the lack thereof, can be seen as a social tool for pointing out when things are out of line. Among other things, our sense of humor is a sense for detecting abnormality. A humorous observation 
is often an exposition of something atypical or abnormal. "Normal" is the standard, against which the emerging occurrences in life are compared. Normal is relative to its point of reference as it changes with the context - what is normal in one situation is abnormal in another one. Bergson describes laughter as a "social gesture", and theorizes that comedy exists to serve society by exposing unsociable behavior to laughter and mockery, which subsequently corrects the course [46. The essence and the foundation of Bergson's theory is that we agree upon certain models of accepted social behavior, and that normality exists in some form - but also conceding that the boundaries of normality are impossible to define.

Veatch [47 hypothesizes that humor occurs when a situation is perceived as a violation of a subjective moral principle, while it is also simultaneously conceived as being normal. This basically means that when the sense of normality is lost in a situation, there can be no perceived humor in it. Furthermore, Veatch points out that there is nothing objective about humor, and that both normal, and violation of normal, are subjective views of a situation. McGraw and Warner [48] share a similar view, in that "humor only occurs when something seems wrong, unsettling or threatening (i.e. a violation), but simultaneously seems okay, acceptable, or safe (i.e. benign)." According to them, a pun is a linguistic violation that still makes sense grammatically, and sarcasm is a violation of accepted rules of a conversation, by meaning the opposite of what is said. Hietalahti [49] refers to this as one of the paradoxes of humor, and points out that "The paradoxical nature of the world, human beings and life in general also has its impact on the nature of humor. Incongruity theory explains how humor is produced by paradoxes; that there is a contradiction in play at which we laugh to resolve."

Because all games are artificial, they often face challenges in normalizing their own fictional domains, which the players are required to accept as their new short-term realities. Video games need to normalize the rules that govern them, but also the worlds in which they are set. Comedy can be used as an indirect method to communicate the state of affairs of the game world to the player. For instance, South Park: The Stick of Truth ${ }^{22}$ takes its world from the television show - which in itself is a satirical take on the real world - and uses it as a backdrop for a live action role-playing game, involving the children of the South Park. As every other child in the town is in pretense that wizards, elves and magic are real, the player is expected to play along. The combat is turn-based, because according to he grand wizard king Eric Cartman, it is faithful to how battles were fought in the "olden times". The world in the background keeps on moving as the role-playing children politely wait for their turn in combat. "I know it's lame but that's how we are doing it," Cartman explains to one of the characters growing impatient of the system. The roleplaying subplot of Stick of Truth is satire of the game's self-deployed magic circle, and the introspective humor helps to anchor the gameplay mechanics to

${ }^{22}$ Ubisoft (2014), PlayStation 3. 


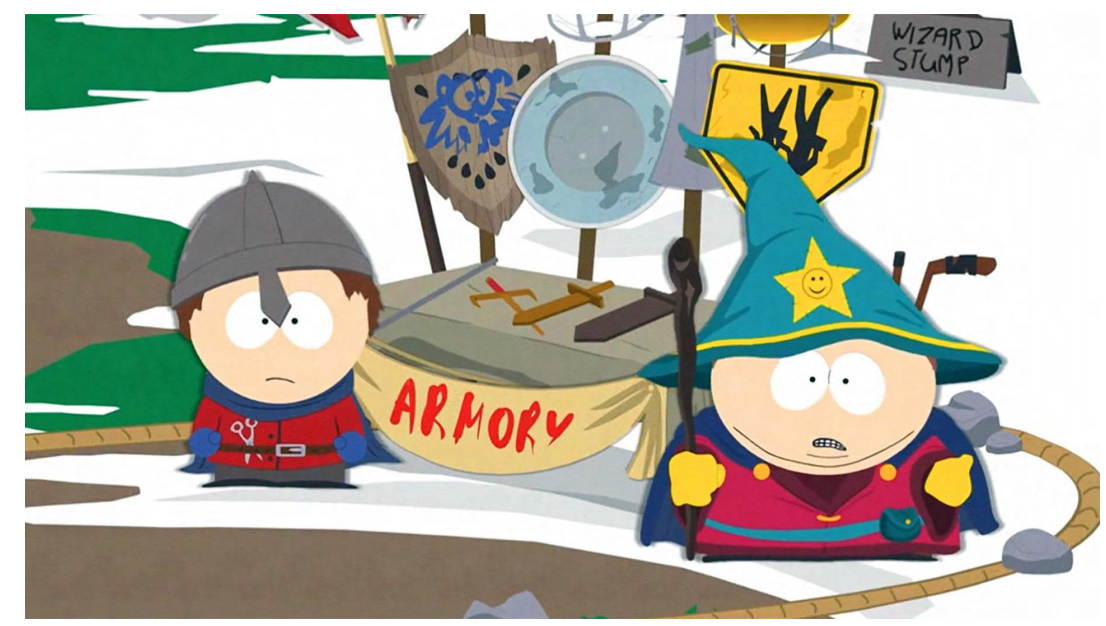

Figure 6: A screen-shot from South Park: The Stick of Truth, showing its grand wizard.

the fiction of South Park. The game never lets the player forget that its rules are arbitrary and that its plot concerns kids playing with wooden swords.

For the audience, comedy is not so much about questioning than it is about submitting to a world view-i.e., someone else has done the questioning and the thinking, and the audience is there just to enjoy the conclusions. Lippman [50] suggests that not only does comedy reference what is considered normal, but it can actively transform it as well. Having studied romantic comedy films featuring overly persistent men, Lippman discovered that the female viewers of this genre are more likely to tolerate similarly obsessive behavior by men in real life. Thus, comedy is also an instrument of normalization. It can transform culture and change our expectations about the nature of reality. A comedic observation nudges the audience's subjective reality, and the induced laughter is a trick that makes the audience momentarily agree with the presented view. Game designers can use observational comedy as a tool to reveal inconsistencies and illogicalities within their game worlds, to point out abnormality. For instance, when viewed through a comedic lens, the world of the Super Mario games becomes filled with figurative question marks - in addition to being filled with actual, physical question marks. The relationships and the motivations of the characters fluctuate depending on the day. Bowser is either a villain terrorizing the Mushroom Kingdom, or a good enough comrade with whom it is safe to play golf or share a go-kart. The personality turnaround is never explained or questioned by any of the characters involved. Although the Super Mario games are built on jolly aesthetics and euphonics, there is little to no humor in the world. The hills and the clouds and the mushrooms all smile and laugh, but not as a result of any comedic occurrence. Jokes would get lost in the world of Super Mario, as laughing is the default state for existing. The baseline for what is considered normal in the world is already glee. Because so little is explained to the player, the "all smiles" design principle can be interpreted as either festive, 
or deranged.

Comedy can even result from highlighting the "normal", to reveal the contrast with the "ludicrous". An embodiment of this type of contrasting is a character type referred to as the "comedic foil". A comedic foil contrasts another character in a way that highlights comicality in a scene. A comic foil character, who is the voice of reason, is referred to as the "straight man", and is used to momentarily establish or restore normality in a comic scene. The juxtaposition of ludicrous with the normal creates a point of reference that highlights the humorous angle. For instance, the television show The Offict ${ }^{23}$ constantly utilizes the straight man dynamic when delivering its jokes.

\subsection{Comic relief}

Many theorists recognize that humor has a tension-releasing function. Some have suggested that it may even be a defining quality in all things funny [2. Most jokes rely on built up tension and punchlines that deflate it. The tension relieving aspect of humor becomes evident in stressful or anxiety-provoking situations, where the inclusion of humor engenders positive thoughts and emotions. Gross and Muñoz [51] regard humor as an emotion regulating mechanism that is beneficial for a person's mental health. Relief theory considers all amusing scenarios as a consequence of built-up tension, and the function of humor as a release valve for psychological distress. Humor enables people expressing their inner desires and helps them to cope with shock and the hardships of life [52, 53]. Some researchers consider laughing as a sort of biological false alarm [54, a vocal signal that is set off when a presumed danger is exposed as non-threatening.

Humor that cuts through the tension has been adapted to a technique called comic relief. Comic relief comes into action when the suspense of a scene needs a sudden halt. Sometimes a comic relief appears as a personification, other times as bathos - an incongruous technique that abruptly transforms a serious scene to ludicrou ${ }^{24}$ - which can be a piece of dialogue or a sudden comedic occurrence. By doing so, comic relief momentarily reframes the situation at hand.

Most games are designed to provoke emotional excitement, but this intensity can easily provoke frustration in the players. Because the humorous and the competitive mindsets rarely exist simultaneously in the same person, comic relief can be used to quickly discharge the built-up tension and restore the player to a more tranquil frame of mind. Dormannn and Biddle [9] recognize the players' appreciation for the brief, intentional or unintentional, moments of comic relief that they experience in games, claiming that these moments hold almost cathartic value.

Comic relief is extensively used in Uncharted 2: Among Thieves 25 which is a game of high intensity gunplay. The game acknowledges the stress that it

\footnotetext{
${ }^{23}$ The Office (2005-2013), NBC.

${ }^{24}$ Defined by Alexander Pope in a short essay, called "Peri Bathous, or the Art of Sinking in Poetry", published in 1728.

${ }^{25}$ Sony Computer Entertainment (2009), PlayStation 3.
} 
generates through the talkative main character, Nathan Drake, who is a complete opposite of the silent protagonist trope. For example, after a narrow escape from a collapsing building, Drake bursts into laughter and comments under his breath: "We were almost in that!" The line is a cue for the player to relax and take a breath before the next high intensity encounter commences. Drake's voiced observations guide the player to the right direction, both navigationally and emotionally. They reflect the player's state of mind while undergoing these nerve-racking scenes. As such, Drake is the protagonist, the narrator, and the comic relief.

The moments of interactive comic relief can also appear as incidentally triggered mechanical implementations. For instance, when the player hijacks a car in Grand Theft Auto IV $\sqrt{26}$ its rightful owner might resist the attempt and grab the car door handle, only to get dragged along with the fleeing vehicle. Other times, the vehicle might have passengers inside, who remain seated and keep screaming, while the player commits the car theft and drives away. Yet some other times, the car's owner might even surprise the car-nabbing player by pulling out a gun start shooting. Such transgressive conduct, which would of course be horrifying in real life, become amusing in the fictive world of Grand Theft Auto. The inability to obtain a vehicle can be considered a failure by the player to fulfill their objectives, but the unpredictable comedic twists lessen the disappointment. Dormannn and Biddle 9] maintain that humor meditates changes in our emotional state, providing relief to situations that would otherwise frustrate or discourage.

\subsection{Superiority humor}

Gruner's superiority theory [55] considers humor as a form of aggression, and regards joking as a friendly game where laughing equals winning-and inversely, not laughing equals losing. By winning, Gruner means "reaching a specific condition or place", which in the case of humor means getting the final laugh. While winners are usually recognized with a reward, Gruner admits that it is not always easy to figure out what has been won, and laughter is not necessarily the best metric for measuring who is ahead in the race.

Similarly, Carr and Greaves [56] acknowledge the will to win as being a fitting motivation behind a lot of humor and a useful explanation for our response to certain jokes. They also note that if a comedian telling a clever joke is considered to be the winner, then the audience should be considered as the losers, even though they are rewarded with laughter. However, it is also true that sometimes joking can be snide, unkind, or even outright mean, and the term "butt of a joke" can be interpreted as signifying the loser in the comic play. While the competitive antagonistic humor is not the only reason we laugh, it translates very well into the dueling nature of many video games.

It is important to point out here that the acts of aggression make compelling gameplay mechanics. In fact, since so many video games utilize aggressive acts

${ }^{26}$ Rockstar Games (2008), PlayStation 3. 
such as killing as the only way to interact with their game world, aggression could be considered a defining quality for the medium of video games. While video games did not invent the action genre, it is apparent that they resort to violence more often than most other entertainment media. Conflict is a major tension-generating component in game narratives, and killing just happens to be an efficient way to resolve such a conflict. Ken Levine, the creator of the video game BioShock 27 points out that shooting in games resolves many design problems: "You have weapons, you have enemies, you have conflict coming at you." (quoted in [57]). However, Levine also recognizes that the consumers of the interactive entertainment have increasing confidence in the industry to express itself in more diverse ways. Although violence, which generates a feeling of empowerment, resonates with many players, there are other ways of simulating the sensation of empowerment. For example, the feeling of being in control also comes with laughter, and can be incorporated into video games through comic elements.

In many video games aggression humor often takes the form of insult comedy. An early example of the use of insult comedy in video games is in the comedic pirating adventure game The Secret of Monkey Island ${ }^{28}$. It introduced an activity called insult sword fighting, in which the player engages in a sword fight with an opponent, but throughout the fencing the duelists take pauses to launch insults at each other (see Figure 7). The actual insults and comebacks are a little lukewarm, but there is the added value of figuring out what most fitting line is. The jokes are funnier because the game make the players feel like they came up with them. The insults are not observational, as the game does not take into account any of the opponents' looks or mannerisms, but its comedic shaming is an inventive substitute for violence.

However, insult comedy runs the risk of getting the players agitated when they are at the receiving end of the festive abuse. Multiplayer games with text or voice chats are the most notorious example of aggression overrunning comedy. Lighthearted banter can abruptly turn into demoralizing insults, that can result in players quitting the game and never returning. Salen and Zimmerman 27] contend that in a "cutthroat social ecosystem of the playground, games are often contexts for asserting and challenging social power." When the feelings boil over, humor ceases to exist and communication becomes demeaning. It is clearly better when a game sets up boundaries for players' behavior, by either moderating or constraining them, specially when there are other players involved. For example, if the ridicule is directed at the characters whom the players are playing, and not so much towards them or their abilities, then the game has a better chance of making the players laugh. Ron Gilbert (quoted in [58]) likens the effect to the player analogously divorcing themselves: "I don't think anybody, when they're playing Monkey Island or The Cave, thinks they are those people on the screen, but they definitely empathize with them, and

\footnotetext{
${ }^{27} 2 \mathrm{~K}$ Games (2007), Windows.

${ }^{28}$ Lucasfilm Games (1990), MS-DOS
} 


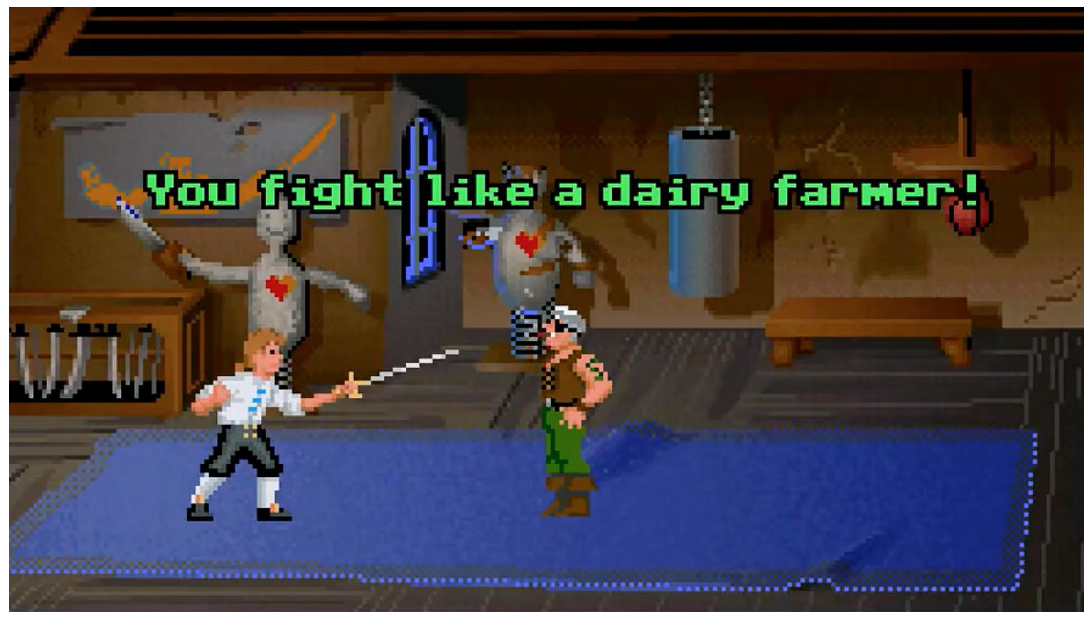

Figure 7: A screen-shot from The Secret of Monkey Island, showing its insult sword fighting.

they do relate to them, and they do feel a big attachment to them. So you have to be careful that the humor is making fun of the character and not what the player did with the character, because then you're insulting the player and not the character." Despite this, as Dormann and Biddle 9] note, although humor can be used as to humiliate the opponent, it can also make the aggressiveness and tenseness that are associated with competitive gameplay more acceptable and endurable.

In real life, one of the more popular forms of insult comedy is called "roasting", which refers to an event where an individual is ridiculed for the entertainment of spectators. Traditionally a roast set-up consists of the guest of honor - preferably a notable figure, who is seated facing the audience - and the roastmaster who acts as the master of ceremony. Roasting, being a form of play, and coinciding with Gruner's adaptation of superiority theory [55], can be easily translated to the form of video games as well. In order for the game to be able to roast the players, it first needs to be aware of their ventures. Video games have the unique ability to track what players do in them, where they go, what they decide to do and so on. For inclusion of comic elements, such as roasting, player-tracking and data collection has far greater potential than what it is currently being done in video games. Most games scan players' motions and actions in great detail, but only a few games make any comic observations, and even fewer make comic remarks based on such observations.

Some games have, however, toyed with the idea of comically insulting their players based on their actions - with varying results. For example, the Seaman 29 game makes fun of the player for engaging with it too frequently, while

\footnotetext{
${ }^{29}$ Sega (1999), Dreamcast.
} 
Earthworm Jim ${ }^{30}$ and Punch-Out!! ${ }^{31}$ make fun of the player for choosing a low difficulty level. There are also a few games that will call players out when they are caught cheating. For instance, when a players attempts to cheat by resetting the console in Animal Crossing ${ }^{32}$, a character called Resetti appears on the screen yelling, "I said not to reset!", and then gives along lecture about the importance of saving before turning the game off.

\section{Discussion}

Table 1 provides a summary of the results of our analysis of all the various types of methods used for incorporating comedy into ludonarrative of video games. As this analysis shows, there is no single way of making the player laugh. However, while from the point of view of humor, any kind of laugh fills its purpose, when trying to define a ludonarrative comedy genre, not all laughs can be treated as equal.

The process of defining whether a given game could be considered a work of comedy requires considering a number of factors. The first factor to consider is whether mirth is the predominant emotion for the player while playing the game, and if so, then try to consider the main source of humor that is resulting in the player's mirth. As discussed, in ludonarrative comedy, humor stems from either the narrative elements of the game or from its mechanics and environment. We have also pointed out, that although unintended and surprising occurrences in video games (e.g., due to bugs and glitches) can undoubtedly be comical, since such humor is not purposefully designed as part of the ludonarrative of a game, it is not considered as comedy here. The main point to emphasize is this, while comedy often aspires to appear as fortuitous, intentionality is what separates it from other forms of humor.

The second factor to consider is that all comedy has a premise which bridges the gap between its comic reality and the actual reality. The comic premise can be discerned by identifying the conflicts - inner, local (interpersonal), and global - that lead up to it. What should be taken into account when designing these ludonarrative conflicts, is that the player interacting with the game also plays a part in the development of the conflicts, rather than simply being the audience observing the pre-planned comic conflict.

Yet another factor to consider is related to the visuality of comedy. Video games are largely part of an aesthetic medium, and as such, the classic directorial technique of showing instead of telling also applies to them. However, instead of simply showing something comic to the players, often the better option is to make them perform it themselves. For ludonarrative comedy, embracing players as the comedians is not obligatory, but giving them a more engaging and enjoyable role to play is. Games are built around the assumption that their

\footnotetext{
${ }^{30}$ Interplay Entertainment (1994), Sega Genesis.

${ }^{31}$ Nintendo (2009), Wii.

${ }^{32}$ Nintendo (2001), Gamecube.
} 
Table 1: A summary of the types of methods used for incorporating comedy into ludonarrative of video games, with a few illustrative examples of each type.

\begin{tabular}{|c|c|c|c|}
\hline & Methods & Elements & Examples \\
\hline \multirow{3}{*}{ 承 } & Visuality & $\begin{array}{l}\text { visual style } \\
\text { characters } \\
\text { animations }\end{array}$ & $\begin{array}{l}\text { Katamari Damacy } \\
\text { Outcast } \\
\text { Super Mario Odyssey } \\
\text { Enviro-Bear 2000 } \\
\text { Surgeon Simulator }\end{array}$ \\
\hline & Sources & $\begin{array}{l}\text { through-storytelling } \\
\text { through-mechanic }\end{array}$ & $\begin{array}{l}\text { Grand Theft Auto } \\
\text { The Legend of Zelda } \\
\text { The Stanley Parable }\end{array}$ \\
\hline & Conflicts & $\begin{array}{l}\text { inner } \\
\text { local (interpersonal) } \\
\text { global }\end{array}$ & $\begin{array}{l}\text { Octodad } \\
\text { Untitled Goose Game } \\
\text { Who's Your Daddy } \\
\text { Gang Beasts } \\
\text { The Sims } \\
\text { Portal } \\
\text { Katamari Damacy } \\
\text { Frog Fractions } \\
\end{array}$ \\
\hline \multirow{5}{*}{ 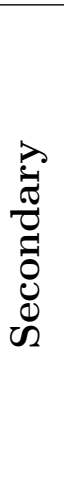 } & Humorous worlds & player's mood & Jazzpunk \\
\hline & Environmental storytelling & repetition-variation & many games \\
\hline & Challenging normality & $\begin{array}{l}\text { subjectivity } \\
\text { paradoxes }\end{array}$ & $\begin{array}{l}\text { South Park } \\
\text { Super Mario }\end{array}$ \\
\hline & Comic relief & $\begin{array}{l}\text { comedic foil } \\
\text { tension-release }\end{array}$ & $\begin{array}{l}\text { Uncharted } 2 \\
\text { Grand Theft Auto }\end{array}$ \\
\hline & Superiority humor & $\begin{array}{l}\text { gloating } \\
\text { insult comedy } \\
\text { roasting }\end{array}$ & $\begin{array}{l}\text { Punch-Out!! } \\
\text { Seaman } \\
\text { Earthworm Jim } \\
\text { Animal Crossing } \\
\text { The Secret of } \\
\text { Monkey Island }\end{array}$ \\
\hline
\end{tabular}

audiences wish to be an active component in the unfolding of the narrative. Making players a component in the comedy-making can enhance their experience with the game. Whether the player is made an initiator - who simply triggers a humorous event - or an implementer - who actively performs in such an eventtheir role is always more significant than the one of an observer. Comic playsignifying such visual gags that require player input and result in emergent humorous narratives - is a defining element in ludonarrative comedy.

Lastly, it is also important to consider the role of other secondary factors, which we have defined here as comic enhancers. Most successful comedies ordinarily feature humor enhancers, that give every comic production its personality. We have considered five different categories of these - often inter-related-comic enhancers which can be used to highlight ludonarrative comedy elements of video 
games. These enhancers should be used, not only to make the comic premise more evident, but also to reveal the baseline for normality in the comic realm of video games.

\section{Conclusions}

In this paper, we have analyzed existing video games to identify and categorize various methods of featuring comedy through ludonarrative elements of video games. We have grouped these methods into three primary categories: (1) adopting a particular visual style, (2) choosing a primary source of embedded or emergent comedy, and (3) creating one or more types of inner, local (interpersonal), or global conflicts. We have also defined five secondary categories of methods which can be used as comic enhancers, by: (1) creating humorous worlds, (2) adding environmental storytelling elements, (3) challenging the normality of the game world, (4) providing comic relief, and (5) generating superiority humor.

The strengths and weaknesses of the medium of video games should be acknowledged and addressed by their creators when pondering what type of comedy could make players laugh. Although some comedic genres, like slapstick or surreal humor, are currently more represented in video games than others, there does not seem to be any narrative or ludic limitations preventing more marginalized genres, such as satire or romantic comedy, to become more popular.

Video games are still very much in the process of developing their own comic language. The sole presence of the player, and the dual roles the player has as the lead actor and a member of the audience, means that the rules of the comic language of video games will vastly diverge from what has been agreed and learned previously in other comic media. For their creators, this lack of established conventions means that the field of video games is a playground for experimentation. Whether it is the mirth-invoking systems of a video game, its responsiveness to the players' mischievous actions, or the artificial stupidity that interferes with players' objectives, it is clear that ludonarrative comedy is capable of making us laugh in ways that traditional comedy simply do not or cannot.

\section{References}

[1] G. Hookham, M. Meany, The spectrum of states: Comedy, humour and engagement in games, in: Proceedings of the 11th Australasian Conference on Interactive Entertainment, Vol. 167 of CRPIT, ACS, Sydney, Australia, 2015, pp. $25-34$.

URL http: //crpit.com/conf papers/CRPITV167Hookham.pdf

[2] R. Martin, The Psychology of Humor, Academic Press, 2006.

[3] M. Eastman, Enjoyment of laughter, Simon and Schuster, New York, 1936. 
[4] E. B. White, K. S. White, A subtreasury of American humor, New York : Coward-McCann, 1941.

[5] D. H. Monro, Theories of humor, in: L. Behrens, L. J. Rosen (Eds.), Writing and Reading Across the Curriculum, 3rd Edition, Foresman and Company, 1988, pp. 349-355.

[6] J. Vandaele, Humor mechanisms in film comedy: Incongruity and superiority, Poetics Today 23 (2) (2002) 221-249.

URL https://doi .org/10.1215/03335372-23-2-221

[7] C. Hocking, Ludonarrative dissonance in bioshock, [Accessed in March 2019] (2007).

URL http://clicknothing.typepad.com/click_nothing/2007/10/ ludonarrative-d.html

[8] O. Kallio, M. Masoodian, Comedy in the ludonarrative of video games, in: E. Clua, L. Roque, A. Lugmayr, P. Tuomi (Eds.), Proceedings of the IFIP International Conference on Entertainment Computing, ICEC, Springer International Publishing, Pozna, Poland, 2018, pp. 115-126. URL https://doi.org/10.1007/978-3-319-99426-0_10

[9] C. Dormann, R. Biddle, A review of humor for computer games: Play, laugh and more, Simulation \& Gaming 40 (6) (2009) 802-824.

URL https://doi.org/10.1177/1046878109341390

[10] C. Dormann, Fools, tricksters and jokers: Categorization of humor in gameplay, in: D. Reidsma, I. Choi, R. Bargar (Eds.), Intelligent Technologies for Interactive Entertainment, Springer International Publishing, 2014, pp. $81-90$.

[11] A.-M. Grönroos, Humour in video games: Play, comedy, and mischief, Master's thesis, Aalto University (2013).

[12] J. Juul, The game, the player, the world: Looking for a heart of gameness, [Accessed in March 2019] (2003).

URL http://www.jesperjuul.net/text/gameplayerworld/

[13] G. Frasca, Ludology meet narratology: Similitude and differences between (video)games and narrative, [Accessed in March 2019] (1999).

URL http://www.ludology .org/articles/ludology.htm

[14] Z. Quinn, Comedy games: An underexplored genre, [Accessed in March 2019] (2015).

URL http://www.gdcvault.com/play/1021867/ Comedy-Games-An-Underexplored

[15] B. Mackey, No laughing matter: Making humor work in games, [Accessed in March 2019] (2009).

URL http://www.gamasutra.com/view/feature/132586/no_laughing_ matter_making_humor_.php 
[16] N. D. Bell, Responses to failed humor, Journal of Pragmatics 41 (9) (2009) $1825-1836$.

URL https://doi.org/10.1016/j.pragma.2008.10.010

[17] L. Gonzalez, A brief history of video game humor, [Accessed in March 2019] (2004).

URL https://www.gamespot.com/articles/ a-brief-history-of-video-game-humor/1100-6114407/

[18] R. Pratchett, T. Schafer, J. Teti, S. Vanaman, Make 'Em Laugh: comedy in games, [Accessed in March 2019] (2010).

URL http://www.gdcvault.com/play/1012287/ Make-Em-Laugh-Comedy-in

[19] M. Abbott, Knock em dead, [Accessed in March 2019] (2010). URL http://www.brainygamer.com/the_brainy_gamer/2010/07/ comedy.html

[20] S. Totilo, Joystuck: Why aren't video games funny?, [Accessed in March 2019] (2004).

URL http://www.slate.com/articles/technology/gaming/2004/11/ joystuck.html

[21] J. Morreall, Humor and aesthetic education, Journal of Aesthetic Education 15 (1) (1981) 55-70.

URL http://www.jstor.org/stable/3332209

[22] M. Gordon, What makes humor aesthetic?, International Journal of Humanities and Social Science 2 (1) (2012) 62-70.

URL http://www.ijhssnet.com/journals/Vol_2_No_1_January_2012/ $6 . p d f$

[23] M. Furniss, Chuck Jones: Conversations (Conversations with Comic Artists Series), University Press of Mississippi, 2005.

[24] R. Barrett, Chuck Jones' rules for writing road runner cartoons, [Accessed in March 2019] (2015).

URL http://mentalfloss.com/article/62035/ chuck-jones-rules-writing-road-runner-cartoons

[25] T. Zhou, Chuck Jones' rules for writing road runner cartoons, [Accessed in March 2019] (2016).

URL https://vimeo.com/133693532

[26] J. A. Weinstock, Taking South Park Seriously, State University of New York Press, 2008.

[27] K. Salen, E. Zimmerman, Rules of Play: Game Design Fundamentals, The MIT Press, 2003. 
[28] D. Cook, Opinion: A theory about humor in games, [Accessed in March 2019] (2012).

URL http://www.gamasutra.com/view/news/39433/Opinion_A_ Theory_About_Humor_In_Games.php

[29] I. Knox, Towards a philosophy of humor, The Journal of Philosophy 48 (18) (1951) $541-548$. URL http://www . jstor.org/stable/2020793

[30] A. Koestler, The Act of Creation, Hutchinson \& co, London, 1964.

[31] J. Švelch, Comedy of contingency: Making physical humor in video game spaces, International Journal of Communication 8. URL http://ijoc.org/index.php/ijoc/article/view/2687

[32] J. Vorhaus, The comic toolbox how to be funny even if you're not, 1st Edition, Los Angeles Silman-James Press, 1994.

[33] C. Halpern, K. Johnson, D. Close, Truth in comedy : the manual of improvisation, 1st Edition, Colorado Springs, Colo. : Meriwether Pub, 1994.

[34] F. Dille, J. Z. Platten, The ultimate guide to video game writing and design, [Los Angeles] : Lone Eagle, 2007.

[35] I. Bogost, Video games are better without stories, [Accessed in March 2019] (2017).

URL https://www.theatlantic.com/technology/archive/2017/04/ video-games-stories/524148/

[36] B. Vincent, Keep your infant son from death in 'who's your daddy' [Accessed in March 2019] (2015).

URL https://motherboard.vice.com/en_us/article/z43vew/ keep-your-infant-son-from-death-in-whos-your-daddy

[37] K. E. Triezenberg, Humor in literature, in: V. Raskin (Ed.), The Primer of Humor Research, Mouton de Gruyter, 2008, pp. 523-542.

URL https://doi .org/10.1515/9783110198492.523

[38] A. Marszalek, Humorous worlds: a cognitive stylistic approach to the creation of humour in comic narratives, Master's thesis, University of Glasgow (2012).

[39] J. Huizinga, Homo ludens: A study of the play-element in culture, Beacon Press Boston, MA, 1967.

[40] M. Mulkay, On Humor: Its Nature and Its Place in Modern Society, Blackwell Pub, 1988. 
[41] H. Jenkins, Game design as narrative architecture, [Accessed in March 2019] (2004).

URL http://www.electronicbookreview.com/thread/firstperson/ lazzi-fair

[42] J. Lebowitz, C. Klug, Interactive Storytelling for Video Games: A PlayerCentered Approach to Creating Memorable Characters and Stories, Focal Press, 2011.

[43] M. Shermer, The Believing Brain, St. Martin's Griffin, 2012.

[44] F. Rose, The art of immersion: Why do we tell stories?, [Accessed in March 2019] (2011).

URL https ://www . wired.com/2011/03/why-do-we-tell-stories/

[45] A. Walker, Stories in games aren't problems, they're solutions, [Accessed in March 2019] (2017).

URL https://waypoint.vice.com/en_us/article/ez3mkj/ stories-in-games-arent-problems-theyre-solutions

[46] H. Bergson, Laughter: an essay on the meaning of the comic, The Macmillan company, NY, 1911.

[47] T. C. Veatch, A theory of humor, Humor - International Journal of Humor Research 11 (2) (1998) 161-216. URL https://doi.org/10.1515/humr.1998.11.2.161

[48] P. McGraw, J. Warner, The Humor Code: A Global Search for What Makes Things Funny, Simon \& Schuster, 2014.

[49] J. Hietalahti, The dynamic concept of humor - Erich Fromm and the possibility of humane humor, Ph.D. thesis, University of Jyväskylä (2016).

[50] J. R. Lippman, I did it because i never stopped loving you: The effects of media portrayals of persistent pursuit on beliefs about stalking, Communication Research 45 (3) (2018) 394-421.

URL https://doi.org/10.1177/0093650215570653

[51] J. J. Gross, R. F. M. noz, Emotion regulation and mental health, Clinical Psychology: Science and Practice 2 (2) (1995) 151-164. URL https ://doi.org/10.1111/j.1468-2850.1995.tb00036.x

[52] M. Buijzen, P. M. Valkenburg, Developing a typology of humor in audiovisual media, Media Psychology 6 (2) (2004) 147-167.

URL https://doi.org/10.1207/s1532785xmep0602_2

[53] J. C. Meyer, Humor as a doubleedged sword: Four functions of humor in communication, Communication Theory 10 (3) (2000) 310-331. URL https : //doi .org/10.1111/j.1468-2885.2000.tb00194 .x 
[54] V. Ramachandran, The neurology and evolution of humor, laughter, and smiling: the false alarm theory, Medical Hypotheses 51 (4) (1998) 351-354. URL https://doi.org/10.1016/S0306-9877(98)90061-5

[55] C. R. Gruner, The game of humor : a comprehensive theory of why we laugh, New Brunswick, N.J. : Transaction Publishers, 1997.

[56] J. Carr, L. Greeves, The naked Jape : uncovering the hidden world of jokes, London : Michael Joseph, 2006.

[57] D. Takahashi, Game design as narrative architecture, [Accessed in March 2019] (2014).

URL https://venturebeat.com/2014/06/30/ ken-levine-opens-up-on-the-violence-in-bioshock-infinite/

[58] A. J. Agnello, Funny people: Ron Gilbert, maniac mansion and monkey island creator, [Accessed in March 2019] (2012).

URL http://www.gameological.com/2012/07/ funny-people-ron-gilbert/ 